\title{
Information and Communication Technology Infusion Model for Microfinance Bank in the Nigeria
}

\author{
Idowu Peter Adebayo ${ }^{1}$, Balogun Jeremiah Ademola ${ }^{1}$, Komolafe Olufemi ${ }^{2}$, \\ EGEJURU Ngozi Chidozie ${ }^{1}$ \\ ${ }^{1}$ Department of Computer Science and Engineering, Obafemi Awolowo University, Ile-Ife, Nigeria \\ ${ }^{2}$ Engineering Materials Development Institute, Federal Ministry of Science \& Technology, Akure, Nigeria
}

Email address:

paidowu@oauife.edu.ng (I. P. Adebayo)

\section{To cite this article:}

Idowu Peter Adebayo, Balogun Jeremiah Ademola, Komolafe Olufemi, EGEJURU Ngozi Chidozie. Information and Communication Technology Infusion Model for Microfinance Bank in the Nigeria. International Journal of Finance and Banking Research. Vol. 3, No. 4, 2017, pp. 57-69. doi: 10.11648/j.ijfbr.20170304.12

Received: June 29, 2017; Accepted: July 13, 2017; Published: November 1, 2017

\begin{abstract}
This study was motivated by the need of the identification of the ICT devices used in the Nigerian microfinance sector and the formulation of infusion models for each identified ICT device. 126 Structured questionnaires were used to collect information regarding the use of the ICT devices used among respondents of nine (9) microfinance institutions selected from South-Western Nigeria. The different ICT devices identified consisted of smartphones, SMS, e-mails, computer hardware, telephone banking, magnetic ink character recognition (MICR) cheque, bank websites or mobile banking applications, teleconferencing, electronic point-of-sale (E-POS) services and financial ERP software applications. The results showed that majority of respondents who used ICT tools were customers who were traders with a majority age group of around 21-30 years. The results of the study also showed that all ICT tools were adopted in the same year (1999) by bank staffs. The results showed that although all the ICT devices identified were adopted in the same year, it was observed that about $65 \%$ of the respondents adopted smartphones and SMS while less than $16 \%$ of the respondents acquainted themselves with the other devices. Polynomial functions of degree, $m$ were used to formulate the infusion model for each ICT devices identified based on the yearly cumulative distribution of the number of users. The infusion models formulated can be used to estimate the number of users of ICT devices for any given year from the year of adoption of the ICT device.
\end{abstract}

Keywords: Information and Communications Technology, Devices in Use, Infusion Modeling, Agricultural Institute

\section{Introduction}

Microfinance institutions (MFIs) are institutions that provide financial services to poor and low-income households (and their microenterprises), allowing them to better manage their risks, achieve consistent consumption patterns, and develop an economic base [1]. Information and communications technology (ICT) as the use of electronic devices for sending-out, storing and receiving information [2]. ICT is an umbrella term that involves any communication application or device, encompassing; television, radio, satellite systems, cellular phones, computer hardware and software. According to Idowu et al. [3], the last few years has witnessed incredible swift and dynamic execution of ICT which has turned the world into a global village. Investments in ICT have become crucial organizational strategies for survival and competitive advantage. The development in the sector permeates every human activity: social, economic, cultural, religious, political etc. [4]. Technology innovation has influenced the performance of banks and tremendous achievements were achieved in banks networking, service delivery, profitability and customers responses. Microfinance loans tend to have high interest rates in order to recover the high costs of loan administration. ICT can allow MFIs to lower the cost of loan administration, and thus, offer more affordable and flexible loan products to clients [5].

Microfinance is defined as a small-scale financial service for both credit and deposits specifically designed for individuals who farm, fish or herd; operate small or microenterprises that produce, recycle, repair, or trade goods; 
work to gain wages or commissions; gain income from renting out small amounts of land, vehicles, draft animals, or machinery and tools in developing countries, both in the rural and urban areas [6]. It is a provision of financial services for the poor, in which microfinance products are tailored to meet the needs of the poor by using collateral substitution, client participation and taking the service to the poor [7]. At present, the disbursement and payment of microfinance funding are accelerated through cash and cheque-based economies [8]. However, the paper-based system is deemed to be slow and prone to human error, as well as requiring a major annual reconciliation process that involves clients submitting their passbooks to calculate and update their interest charges.

A study by CGAP [9] found that ICT was being used for three different purposes of microfinance worldwide, which are M-commerce, E-money and as a branchless banking channel. M-commerce is the application of current and emerging information and communication technology that includes landline telephone, fax, mobile phone, electronic mail and other internet-based services to conduct businesses [10]; while E-money, or popularly known as e-cash, is a digital equivalent to paper currency and coins that enables secure and anonymous purchases to be made on various items online [11]. Further, a branchless banking channel is a channel that delivers financial services outside the context of conventional bank branches by means of information communication technologies [12]. In enhancing the operation of all microfinance institutions, the European Microfinance Network [13] suggested three types of technology that could be put in place - technology for running the business, clientfacing technology and process automation technology. This advancement is applicable for both Islamic and conventionaloriented microfinance institutions [14].

In running the business, a thorough Management Information System should be in place to ensure that automatic data flow is generated from portfolio management applications to the financial accounting software without any fear of data entry duplication [15]. The function of the Management Information System is also important for providing easy access, detailed and up-to-date information on clients' accounts, balance of disbursements and payments [16]. Client-facing technology could be applied for the disbursal of loans and collection of loan payments through cashless or electronic payment channels, such as mobile banking, Internet-based banking, Automated Teller Machines (ATMs), debit and credit cards, also Point of Sale (POS) devices at retailers [17]. Accordingly, the activities of disbursements, repayments, deposits, withdrawals and money transfers could be completed faster outside of the branch offices of microfinance institutions, with better control and minimum room for error [1]. Process automation or workflow technologies make use of client relationship management systems and mobile solutions in automating several aspects of the loan application process, which includes data gathering, analysis and credit assessment to easily monitor, change and improve process flows.
In Nigeria, O'Flynn [8] found that the means of electronic payment had been increasingly helpful in tackling issues of inflation that make cash transactions a burden to the microfinance institutions as well as the recipients. The issue of inflation arises, as with more recipients being brought in, there will be more cash to be handled and, hence, an increment on the cost of cash administration and management [18]. The migration to cashless payment increases personal security thereby reducing the need to carry large quantities of cash and promotes efficient, secure and convenient transactions. Furthermore, the inducement of cashless transactions provides a route to access and engage the nation's diverse unbanked population in the national finance system. Ahmad [19] identified various issues that surround the slow progress of ICT infusion in microfinance institutions. These include the insufficient organizational and human capacity; unavailability of suitable applications for microfinance; diversity in business processes and frequent changes in procedures; risk of technological failure; diversity of geography and language; unavailability of vendors and their capacity to implement and support ICT solutions; high cost of ICT for microfinance institutions; lack of commitment of management and key decision-makers within microfinance institutions; and also the lack of awareness about the importance of technology.

Nations have also enjoyed an unparalleled increase in productivity as well as sustainable economic growth and development due to this evolving trend. However, this laudable development has not been evenly spread. It is no longer news that Information and Communication Technology (ICT) is arguably the most rapidly growing segment of the world ecosystem [20]. Investments in ICT have become crucial organizational strategies for survival and competitive advantage. From time immemorial, Information has always played a prominent role in human life but the emergence of social progress and the vigorous development in science and technology has immeasurably increased the role of information in every facet of human endeavor [21]. All over the world, ICT are changing the way that things are being done in most organizations today including the financial sectors. Developing countries like Nigeria are not left out in this journey to the adoption of ICT in the banking operations of Nigeria but the gap in knowledge is the ability to understand the rate of adoption and the activities associated with such adoptions among Nigerian banks. There is the need of an infusion model that can be used to estimate the number of people adopting ICT devices given a period of time from the time of adoption, hence this study.

\section{Related Works}

Bada [1] investigated the extent to which Microfinance Institutions (MFIs) use ICT to deliver business services and train staffs in Uganda. The data collected from the survey was analyzed quantitatively and qualitatively. The analysis results indicate that the usage of ICT in microfinance 
business is still low. The usage is fair in business process automation but none in professional skills enhancement through e-learning. Based on the findings of the research it was concluded that there is need to experiment e-learning for professional skills development in Ugandan microfinance institutions. Furthermore, research is needed to test the level of computer technology acceptance in microfinance business.

Dauda and Akingbade [22] assessed employees' and customers' responses of technology innovation on the performance of Nigerian banks. Fifteen (15) major banks were selected for the research with two (2) questionnaires used to test whether there is no significant relationship between technology innovation and customer's satisfaction; and between technological innovation and Nigerian banks employee's performance. Pearson correlation co-efficient was used to analyze the hypotheses. Findings revealed that technological innovation influenced banks employee's performance, customer's satisfaction and improvement in banks profitability. The study recommends effective management of technological innovation for improved employees performance, customer's satisfaction, sustainable profit, increased return on investment, returns on equity, and to promote competitiveness in the Nigerian banking industry.

Agbolade [21], in his study proposed a relationship between the adoption of ICT in Nigerian banks to the level of profitability of the banks. Using a primary data sourced through a structured questionnaire administered to selected banks in South-west Nigeria and the Ordinary Least Square approach econometric techniques, this study examined the nature of the relationship that exist between Banks Profitability and the Adoption of Information and Communication Technology. The data analysis showed that a positive correlation exists between ICT and banks profitability in Nigeria. This implies that a marginal change in the level of the investment and adoption of ICT in the banking industry will result to a proportionate increase in the profit level. This is confirmed by the level of the regression coefficient as well as the factor analysis which revealed that an insignificant size of profit exist without the introduction of the ICT.

\section{Materials and Methods}

This study made use of structured questionnaire as the instrument of data collection from respondents of the selected location in Nigeria to elicit information about the ICT devices used among respondents selected from microfinance banks. This study considered respondents selected from nine (9) microfinance institutions located in Nigeria, namely:
i. Access Bank;
ii. Diamond Bank;
iii. First City Monument Bank (FCMB);
iv. First Bank;
v. Guaranty Trust Bank;
vi. Imowo Microfinance Bank;
vii. Lift Above Poverty Organization (LAPO);
viii. Skye Bank; and

\section{ix. Wema Bank}

The instrument of data collection was used to collect information from the respondents of the study, which included: demographic information, ICT components used at each sites alongside the impact of the ICT components. Following the collection of data from the respondents, the data was analyzed using standard descriptive statistics tools: tables for data presentation and graphs for data presentation. The ICT infusion model was formulated using polynomial expressions of degree, $m$ estimated from cumulative total of users for each year from the year of infusion of each device. The study population identified for this study is the customers and staffs of microfinance institutions. 126 questionnaires were distributed among the respondents with the necessary information provided.

This study incorporated the use of descriptive statistical techniques for the purpose of analyzing the data collected for this study from the respondents. The descriptive statistics methods used helped in the simplification of the data collected in a sensible way by the provision of descriptive summary using frequency tables and charts. The ICT infusion model was formulated using the Microsoft ${ }^{\circledR}$ Excel's built-in functionality for estimating the trend line of graphical tables and charts - which in this case is a polynomial function of degree, $m$. For the purpose of this study, the IT infusion model was formulated as a function of the number of years; $x$ from the base year, $Y_{0}$ up to a required year $Y_{x}$ using a polynomial equation of degree, $\mathrm{m}$ for each identified IT component. Equation 1 shows how to determine number of years, $\mathrm{x}$ that is required to determine the number of users of the ICT devices by the year, $Y_{x}$ from the base year, $Y_{0}$.

$$
x=Y_{x}-Y_{0}+1
$$

The number of ICT devices adopted by the respondents of the nine (9) microfinance institutions for each year, $n_{x}$ was considered as a sequence of terms (equation 2) following which the cumulative total for each successive year was determined till the present year - 2016 (equation 3). Assuming an ICT device which was used starting from a base year, $\mathrm{Y}_{0}=2001$; it will be discovered that the total number of terms in the sequence of users from 2001 till 2015 is $\mathrm{t}=$ $2015-2001+1=15$ years.

$$
n_{x}=n_{1}, n_{2}, n_{3}, n_{4}, \ldots \ldots \ldots, n_{15}
$$

The cumulative total number of ICT devices used by respondents of the 9 locations for each year from the base year till the present year was considered as a series of terms (equation 3). In equation (2), it is observed that each $n_{x}$ for $1 \leq x \leq 15$ represents the number of users of the IT device for each successive year from 2001 till 2015. Equation (2) was converted to a sequence of the cumulative sum of users for each successive year (equation 3 ). Thus each $S_{x} 1 \leq x \leq 15$ represents the cumulative total number of users of ICT devices $x$ years after the base year of infusion, $\mathrm{Y}_{0}$ (see equation 4 ).

$$
\begin{gathered}
S_{x}=n_{1},\left(n_{1}+n_{2}\right),\left(n_{1}+n_{2}+n_{3}\right), \ldots \ldots\left(n_{1}+n_{2} \ldots \ldots+n_{15}\right) \\
S_{x}=S_{1}, S_{2}, S_{3}, S_{4}, \ldots \ldots \ldots \ldots \ldots, S_{15}
\end{gathered}
$$


Where:

$S_{1}=n_{1}, S_{2}=\left(n_{1}+n_{2}\right), \ldots \ldots \ldots, S_{15}=\left(n_{1}+n_{2} \ldots . .+n_{15}\right)$

Hence, the infusion model is thus a polynomial equation of degree $m$ which is the best line fit of the cumulative number of users of each ICT device by year, $\mathrm{Y}_{\mathrm{x}}-x$ years after the base year, $\mathrm{Y}_{0}$. Thus, the IT infusion model is a polynomial fit of equation (4) expressed in terms of $x$ (the number of years after the base year). Hence, the IT infusion model is expressed as shown in equation (5).

$$
S(x)=a+b x+c x^{2}+\ldots \ldots+d x^{n}
$$

Where a, b, c, d $\in \mathbb{R}$

\section{Results and Discussions}

After distribution of the questionnaires among the respondents selected from the nine (9) microfinance institutions using the 126 questionnaires a number of results were identified. Based on the findings of this study, the ICT tools investigated among the 126 respondents chosen for this study were: of smartphones, SMS, e-mails, computer hardware, telephone banking, magnetic ink character recognition (MICR) cheque, bank websites or mobile banking applications, teleconferencing, electronic point-of-sale (EPOS) services and financial ERP software applications.

Following the results of the demographic information of the respondents in order to identify those that make use of these ICT tools within the Nigerian microfinance sector, it was observed that there were more male users $(54.8 \%$ of respondents) than there were female users $(45.2 \%)$ of ICT tools working in the locations selected (Table 1). The results also showed that users within the age interval of 21-450 years (40.5\% for the interval $21-30$ and $26.2 \%$ for the interval 31 40) were more likely to use ICT tools compared to other respondents (Table 2).

Table 1. Sex of respondents selected for this study.

\begin{tabular}{lll}
\hline Gender & TOTAL & \% \\
\hline Male & 69 & 54.76 \\
Female & 57 & 45.24 \\
Total & 126 & 100 \\
\hline
\end{tabular}

Table 2. Age group of respondents selected for this study.

\begin{tabular}{lll}
\hline Age-group & TOTAL & \% \\
\hline less than 20 & 24 & 19.05 \\
$21-30$ & 51 & 40.48 \\
$31-40$ & 33 & 26.19 \\
$41-50$ & 14 & 11.11 \\
above 50 & 1 & 0.79 \\
Missing & 3 & 2.38 \\
Total & 126 & 100 \\
\hline
\end{tabular}

Based on their marital status, the results showed that there is an equal distribution of married and single users of ICT devices among the respondents representing 49.2\% each (Table 3). Based on the category of job description assigned to each of the respondents in their respective location, majority of the respondents were customers with majority being traders $(33.3 \%)$ and students $(29.4 \%)$ and the majority staffs being loan officer (7.9\%) (Table 4$)$.

Table 3. Marital Status of respondents selected for this study.

\begin{tabular}{lll}
\hline Marital Status & TOTAL & \% \\
\hline Married & 62 & 49.21 \\
Single & 62 & 49.21 \\
Missing & 2 & 1.59 \\
Total & 126 & 100 \\
\hline
\end{tabular}

Table 4. Job description of the respondents selected for this study.

\begin{tabular}{lll}
\hline Designation & Total & \% \\
\hline Student & 37 & 29.37 \\
ATM & 3 & 2.38 \\
Customer Service & 2 & 1.59 \\
Loan Officer & 10 & 7.94 \\
Trader & 42 & 33.33 \\
Artisan & 6 & 4.76 \\
Teller & 6 & 4.76 \\
Teacher & 9 & 7.14 \\
Analyst & 1 & 0.79 \\
Civil-servant & 5 & 3.97 \\
Missing & 5 & 3.97 \\
Total & 126 & 100.00 \\
\hline
\end{tabular}

Based on information regarding the educational qualification of the respondents selected for this study; $19.1 \%$ had OND, 39.7\% had BSc/BA, $1.6 \%$ had MSc/MA, 9.5\% had NCE, $7.14 \%$ had SSCE and $18.3 \%$ had HND while $4.76 \%$ did not provide information regarding their educational qualification (Table 5).

Table 5. Education qualification of respondents selected for the study.

\begin{tabular}{lll}
\hline Qualification & TOTAL & \% \\
\hline OND & 24 & 19.05 \\
BSc/BA & 50 & 39.68 \\
MSc/MA & 2 & 1.59 \\
NCE & 12 & 9.52 \\
SSCE & 9 & 7.14 \\
HND & 23 & 18.25 \\
Missing & 6 & 4.76 \\
Total & 126 & 100 \\
\hline
\end{tabular}

Based on the proficiency of the respondents regarding computer use; $2.4 \%$ of respondents were poor, $6.4 \%$ were fair, $36.5 \%$ were average, $45.2 \%$ were good while $7.9 \%$ were excellent; the results further revealed that the majority of the respondents were good with their knowledge of the computer followed by those that had average skills in computer use (Table 6).

Table 6. Computer compliance among respondents selected for the study.

\begin{tabular}{lll}
\hline Compliance & TOTAL & \% \\
\hline Poor & 3 & 2.38 \\
Fair & 8 & 6.35 \\
Average & 46 & 36.51 \\
Good & 57 & 45.24 \\
Excellent & 10 & 7.94 \\
Missing & 2 & 1.59 \\
Total & 126 & 100 \\
\hline
\end{tabular}




\section{Results and discussion of ICT infusion models}

Based on the results of this study, it was discovered that the most commonly used ICT tools between the years 1999 till 2016 were: smartphones (69.8\%), SMS (63.5\%), computers $(34.9 \%)$ and e-mails $(30.2 \%)$ while the least used ICT devices were: teleconferencing (7.1\%), magnetic ink character reader - MICR $(8.7 \%)$ and enterprise resource planning (ERP) software $(10.3 \%)$. The results of the study also show that the number of SMS adopters was influenced by the number of smartphone users both in 1999 while the number of e-mail adopters was influenced by the adoption of computer use (Table 7). The cumulative number of users of each ICT devices from 1999 till 2016 is shown in table 8.

Based on the information displayed in tables 7 and 8 , the year of adoption of each identified ICT device used among the respondents selected from the nine (9) microfinance institutions is shown in Table 9. Table 9 gives a description of the base year (the year of adoption or infusion) of each ICT device used among microfinance banks in Nigeria alongside the initial number of users. All the ICT devices identified were adopted in the same year - 1999. The graphical distribution of the cumulative number of adopters of ICT devices is shown in Figure 1.

Table 7. Distribution of the number of adopters of ICT devices between 1999 till 2016.

\begin{tabular}{|c|c|c|c|c|c|c|c|c|c|c|c|c|c|c|c|c|c|c|c|c|}
\hline \multirow{2}{*}{ ICT Components } & \multicolumn{18}{|c|}{ ICT DEVICE ADOPTERS PER YEAR } & \multirow{2}{*}{ Sum } & \multirow{2}{*}{$\%$} \\
\hline & y99 & y00 & y01 & y02 & y03 & y04 & y05 & y06 & y07 & y08 & y09 & y10 & y11 & y12 & y13 & y14 & y15 & y16 & & \\
\hline Smartphones & 11 & 9 & 4 & 3 & 1 & 0 & 5 & 2 & 0 & 2 & 1 & 7 & 6 & 8 & 6 & 7 & 10 & 6 & 88 & 69.8 \\
\hline SMS & 19 & 9 & 2 & 3 & 0 & 0 & 4 & 3 & 1 & 2 & 2 & 3 & 2 & 6 & 4 & 6 & 7 & 7 & 80 & 63.5 \\
\hline E-mail & 4 & 4 & 1 & 2 & 0 & 1 & 0 & 1 & 2 & 3 & 0 & 2 & 1 & 2 & 2 & 6 & 6 & 1 & 38 & 30.2 \\
\hline Computers & 8 & 3 & 4 & 1 & 1 & 0 & 0 & 3 & 0 & 3 & 4 & 5 & 1 & 0 & 2 & 2 & 4 & 3 & 44 & 34.9 \\
\hline Telephone banking & 2 & 1 & 0 & 2 & 0 & 0 & 0 & 2 & 0 & 0 & 3 & 0 & 1 & 2 & 2 & 3 & 2 & 0 & 20 & 15.9 \\
\hline MICR & 1 & 1 & 1 & 1 & 0 & 0 & 0 & 1 & 0 & 0 & 0 & 1 & 1 & 2 & 1 & 1 & 0 & 0 & 11 & 8.7 \\
\hline Teleconferencing & 1 & 1 & 0 & 1 & 1 & 0 & 0 & 0 & 0 & 0 & 0 & 0 & 0 & 1 & 2 & 1 & 1 & 0 & 9 & 7.1 \\
\hline E-POS & 2 & 1 & 0 & 0 & 0 & 0 & 0 & 0 & 0 & 0 & 0 & 3 & 1 & 1 & 5 & 8 & 5 & 2 & 28 & 22.2 \\
\hline financial Software & 2 & 1 & 0 & 0 & 0 & 0 & 0 & 0 & 0 & 0 & 0 & 0 & 0 & 0 & 3 & 5 & 2 & 0 & 13 & 10.3 \\
\hline
\end{tabular}

Table 8. Distribution of cummulative total number of adopters of ICT devices between 1999 till 2016.

\begin{tabular}{|c|c|c|c|c|c|c|c|c|c|c|c|c|c|c|c|c|c|c|c|c|}
\hline \multirow{2}{*}{ ICT Components } & \multicolumn{18}{|c|}{ ICT DEVICE ADOPTERS PER YEAR } & \multirow{2}{*}{ Sum } & \multirow{2}{*}{$\%$} \\
\hline & y99 & y00 & y01 & y02 & y03 & y04 & y05 & y06 & y07 & y08 & y09 & y10 & y11 & y12 & y13 & y14 & y15 & y16 & & \\
\hline Smartphones & 11 & 20 & 24 & 27 & 28 & 28 & 33 & 35 & 35 & 37 & 38 & 45 & 51 & 59 & 65 & 72 & 82 & 88 & 88 & 69.8 \\
\hline SMS & 19 & 28 & 30 & 33 & 33 & 33 & 37 & 40 & 41 & 43 & 45 & 48 & 50 & 56 & 60 & 66 & 73 & 80 & 80 & 63.5 \\
\hline E-mail & 4 & 8 & 9 & 11 & 11 & 12 & 12 & 13 & 15 & 18 & 18 & 20 & 21 & 23 & 25 & 31 & 37 & 38 & 38 & 30.2 \\
\hline Computers & 8 & 11 & 15 & 16 & 17 & 17 & 17 & 20 & 20 & 23 & 27 & 32 & 33 & 33 & 35 & 37 & 41 & 44 & 44 & 34.9 \\
\hline Telephone banking & 2 & 3 & 3 & 5 & 5 & 5 & 5 & 7 & 7 & 7 & 10 & 10 & 11 & 13 & 15 & 18 & 20 & 20 & 20 & 15.9 \\
\hline MICR & 1 & 2 & 3 & 4 & 4 & 4 & 4 & 5 & 5 & 5 & 5 & 6 & 7 & 9 & 10 & 11 & 11 & 11 & 11 & 8.7 \\
\hline Teleconferencing & 1 & 2 & 2 & 3 & 4 & 4 & 4 & 4 & 4 & 4 & 4 & 4 & 4 & 5 & 7 & 8 & 9 & 9 & 9 & 7.1 \\
\hline E-POS & 2 & 3 & 3 & 3 & 3 & 3 & 3 & 3 & 3 & 3 & 3 & 6 & 7 & 8 & 13 & 21 & 26 & 28 & 28 & 22.2 \\
\hline financial Software & 2 & 3 & 3 & 3 & 3 & 3 & 3 & 3 & 3 & 3 & 3 & 3 & 3 & 3 & 6 & 11 & 13 & 13 & 13 & 10.3 \\
\hline
\end{tabular}

Table 9. Year of infusion (base year, $y_{0}$ ) for each ICT tools used among Nigerian microfinance institutions.

\begin{tabular}{lllll}
\hline ICT Device & Year of Infusion & Initial Users & Present Users & Percentage number of users (\%) \\
\hline Smartphones & 1999 & 11 & 88 & 69.8 \\
SMS & 1999 & 19 & 80 & 63.5 \\
E-mail & 1999 & 4 & 38 & 30.2 \\
Computers & 1999 & 8 & 44 & 34.9 \\
Telephone banking & 1999 & 2 & 20 & 15.9 \\
MICR & 1999 & 1 & 11 & 8.7 \\
Bank website/Mobile app & 1999 & 2 & 19 & 7.1 \\
Teleconferencing & 1999 & 1 & 9 & 22.2 \\
E-POS & 1999 & 2 & 28 & 10.3 \\
financial Software & 1999 & 2 & 13 & \\
\hline
\end{tabular}

For the purpose of formulating the IT infusion model using the polynomial function $S$ (x) with respect to $x$ which represents the number of years after the base year, $\mathrm{Y}_{0}$ for each ICT device considered for the study. The Microsoft Excel Data Analysis Toolkit for the estimation of trend lines using polynomial fits from the graphs and charts of the cumulative total number of ICT users was used to formulate the infusion model for each ICT device. Thus, the total number of users of ICT tools can be determined for a given year, $Y_{x}$ given the number of years $x$ from the year of infusion as determined from equation 1 using equation 5 .

a. Infusion model for the use of smartphones

Following the results of cumulative sum of the number of users of smartphones among microfinance banks in Nigeria, it was observed that the year of infusion was 1999 with 11 initial users. Using equation 1, the number of years from 
1999 till 2016 is 18 years which corresponds to the 18 points of the cumulative frequency distribution curve shown in figure 2 . In figure 2 , the base year, $Y_{0}$ is point $x=1$ which corresponds to 11 on the $\mathrm{y}$-axis while each consecutive year, $Y_{x}$ on the $\mathrm{x}$-axis corresponds to the total number of users of smartphones $x$ years after the base year (year of infusion).
Using the auto-generated polynomial that forms the best fit (black line) for the use of smartphones from the cumulative distribution in table 8 , the results showed that the infusion model for the use of smartphones can be represented using a polynomial of degree $m=4$ as shown in equation 6 which had a coefficient of determination, $\mathrm{R}^{2}=0.9965$.

$$
S(x)=-0.0035 x^{4}+0.1582 x^{3}-2.1772 x^{2}+13.106 x+0.2982
$$

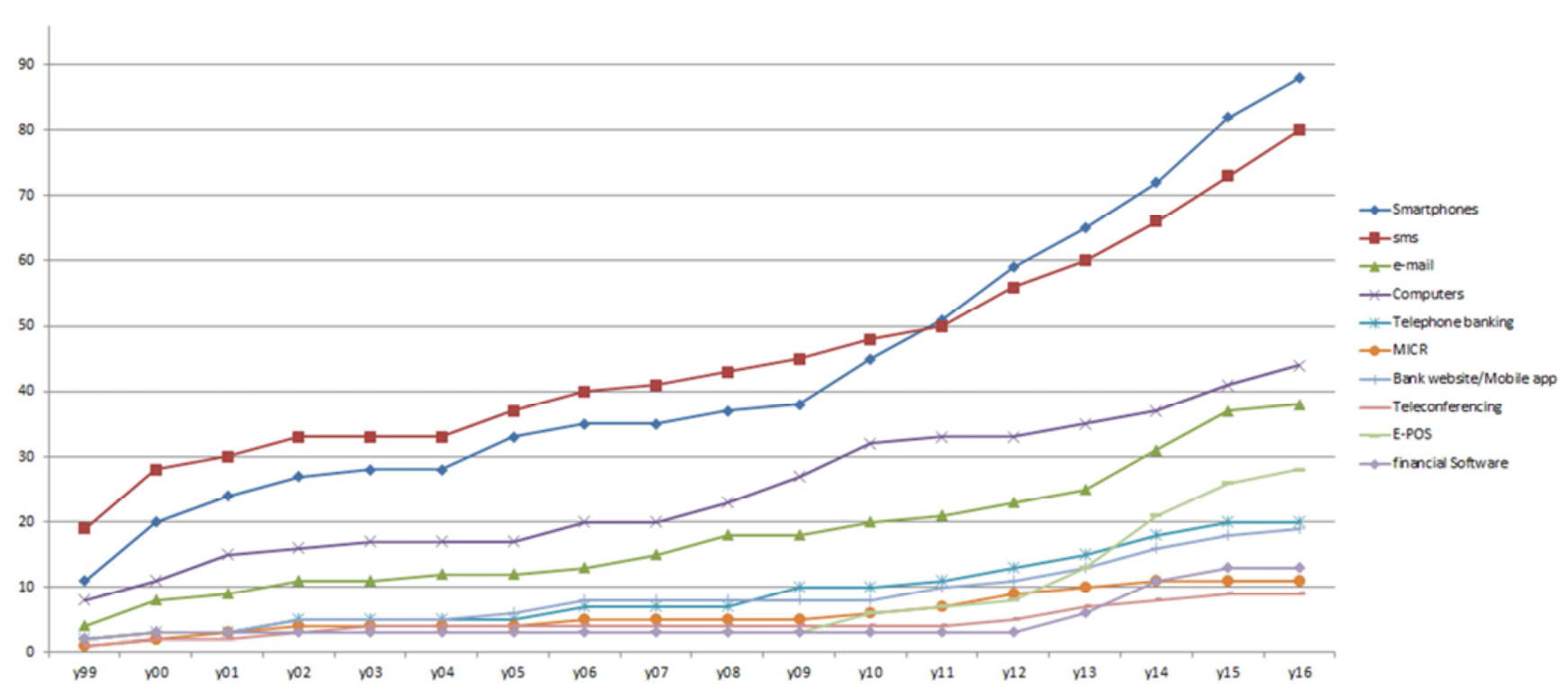

Figure 1. Graphical plot of the cumulative total user of ICT tools between 1999 till 2016.

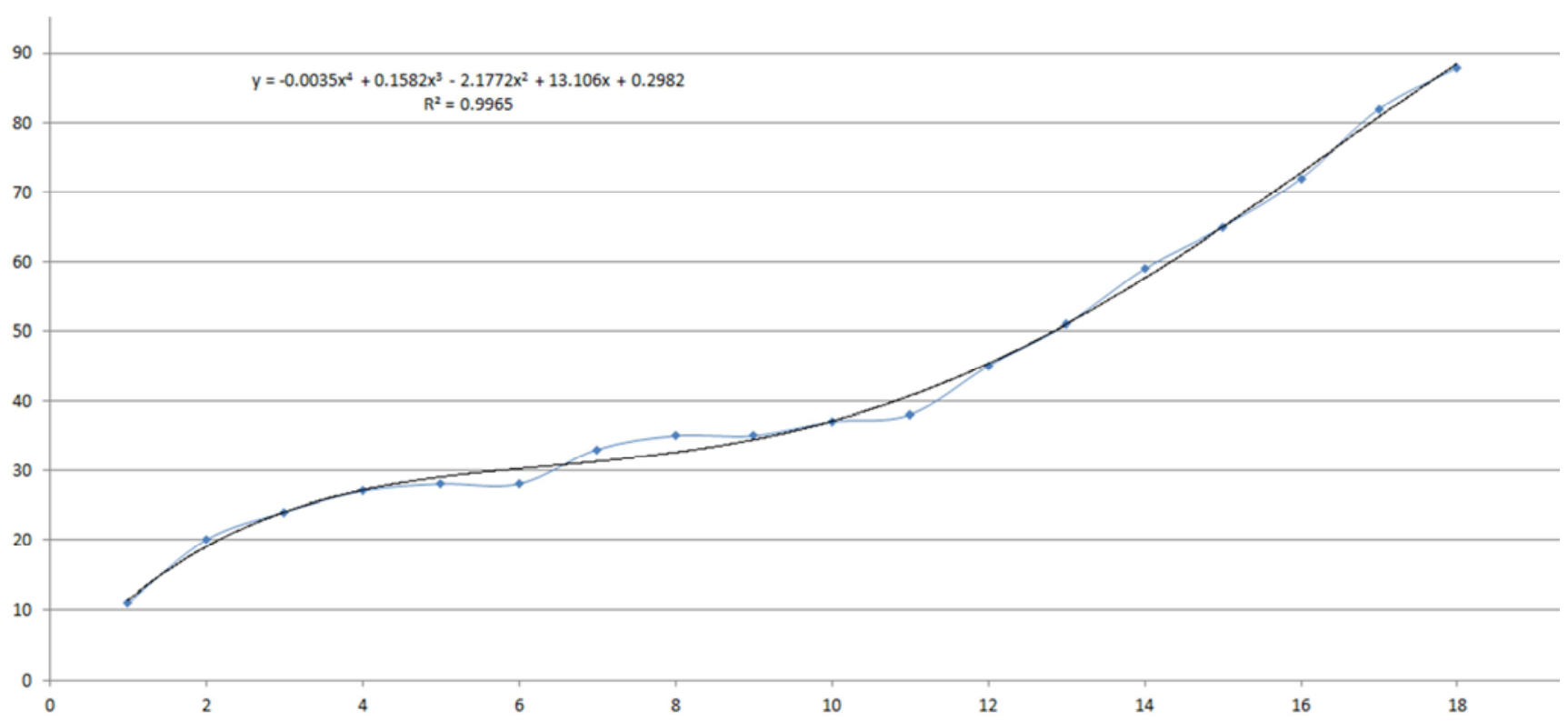

Figure 2. Polynomial fit of the infusion model for smartphones users.

b. Infusion model for the use of SMS services

Following the results of cumulative sum of the number of users of SMS users among microfinance banks in Nigeria, it was observed that the year of infusion was 1999 with 19 initial users. Using equation 1, the number of years from 1999 till 2016 is 18 years which corresponds to the 18 points of the cumulative frequency distribution curve shown in figure 3 . In figure 3 , the base year, $Y_{0}$ is point $\mathrm{x}=1$ which corresponds to 19 on the $\mathrm{y}$-axis while each consecutive year, $\mathrm{Y}_{\mathrm{x}}$ on the $\mathrm{x}$-axis corresponds to the total number of users of SMS x years after the base year (year of infusion). Using the auto-generated polynomial that forms the best fit (black line) for the use of SMS from the cumulative distribution in table 8 , the results showed 
that the infusion model for the use of SMS can be represented using a polynomial of degree $m=4$ as shown in equation 7 which had a coefficient of determination, $\mathrm{R}^{2}=0.9947$.

$$
S(x)=-0.001 x^{4}+0.0581 x^{3}-0.9376 x^{2}+7.3385 x+14.275
$$

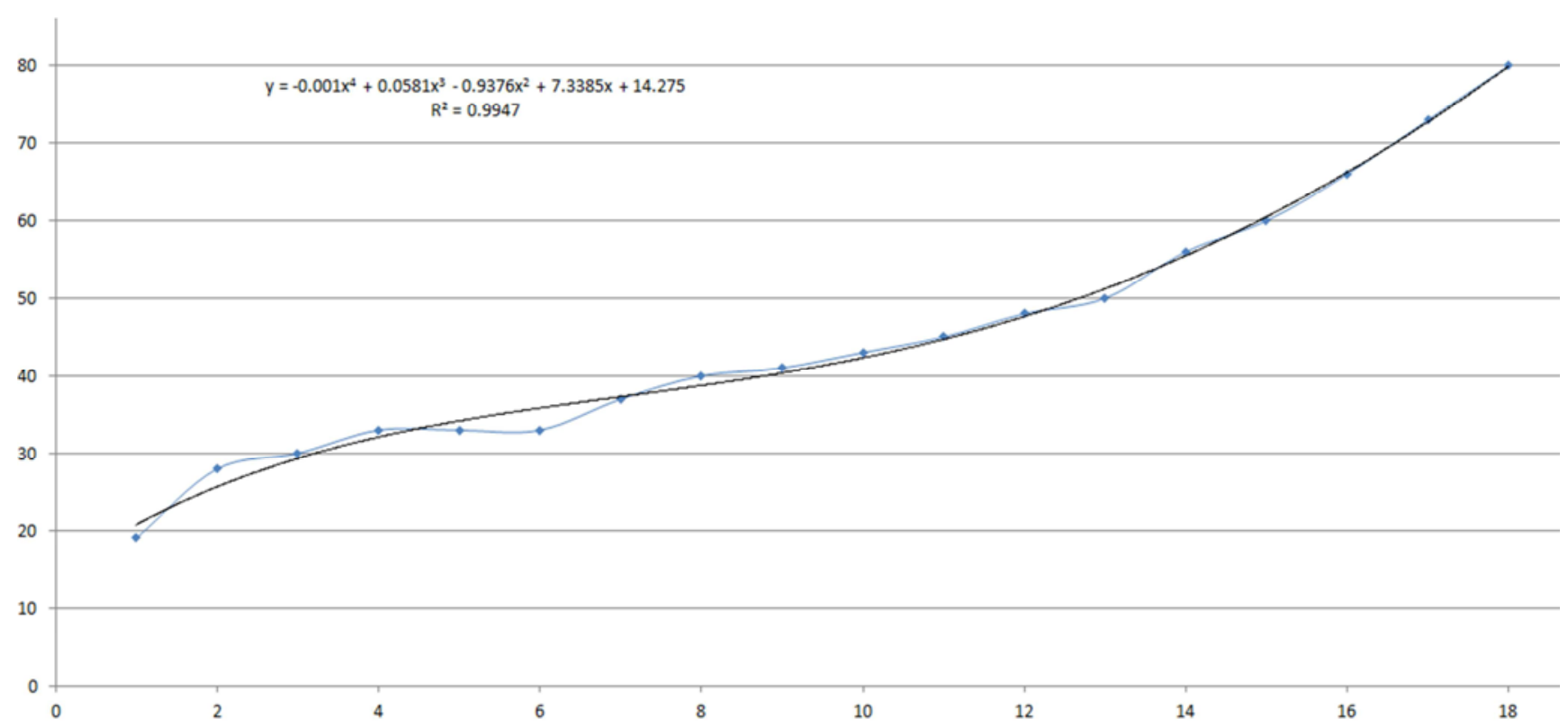

Figure 3. Polynomial fit of the infusion model for SMS users.

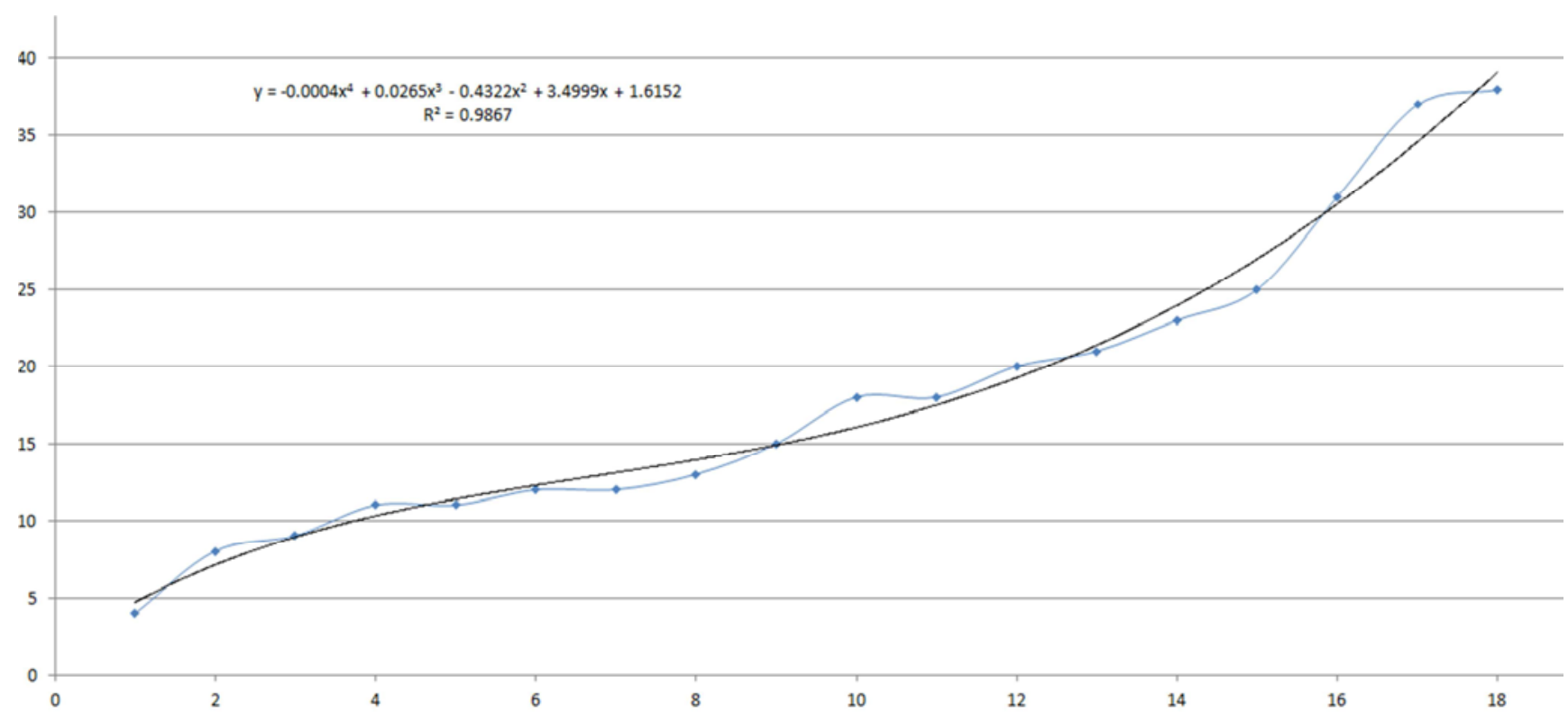

Figure 4. Polynomial fit of the infusion model for e-mail users.

c. Infusion model for the use of e-mail services

Following the results of cumulative sum of the number of users of e-mail users among microfinance banks in Nigeria, it was observed that the year of infusion was 1999 with 4 initial users. Using equation 1, the number of years from 1999 till 2016 is 18 years which corresponds to the 18 points of the cumulative frequency distribution curve shown in figure 4 . In figure 4 , the base year, $Y_{0}$ is point $\mathrm{x}=1$ which corresponds to 4 on the $y$-axis while each consecutive year, $Y_{x}$ on the $\mathrm{X}$-axis corresponds to the total number of users of e-mail $\mathrm{x}$ years after the base year (year of infusion). Using the autogenerated polynomial that forms the best fit (black line) for the use of e-mail from the cumulative distribution in table 8 , the results showed that the infusion model for the use of email can be represented using a polynomial of degree $m=4$ as shown in equation 8 which had a coefficient of determination, $\mathrm{R}^{2}=0.9867$.

$$
S(x)=-0.0004 x^{4}+0.0265 x^{3}-0.4322 x^{2}+3.4999 x+1.6152
$$




\section{d. Infusion model for the use of computers}

Following the results of cumulative sum of the number of users of computers users among microfinance banks in Nigeria, it was observed that the year of infusion was 1999 with 8 initial users. Using equation 1, the number of years from 1994 till 2016 is 18 years which corresponds to the 18 points of the cumulative frequency distribution curve shown in figure 5 . In figure 5 , the base year, $Y_{0}$ is point $\mathrm{x}=1$ which corresponds to 8 on the $y$-axis while each consecutive year,
$\mathrm{Y}_{\mathrm{x}}$ on the $\mathrm{x}$-axis corresponds to the total number of users of computers $x$ years after the base year (year of infusion). Using the auto-generated polynomial that forms the best fit (black line) for the use of computers from the cumulative distribution in table 8 , the results showed that the infusion model for the use of computers can be represented using a polynomial of degree $m=4$ as shown in equation 9 which had a coefficient of determination, $\mathrm{R}^{2}=0.9907$.

$$
S(x)=-0.0035 x^{4}+0.1582 x^{3}-2.1772 x^{2}+13.106 x+0.2982
$$

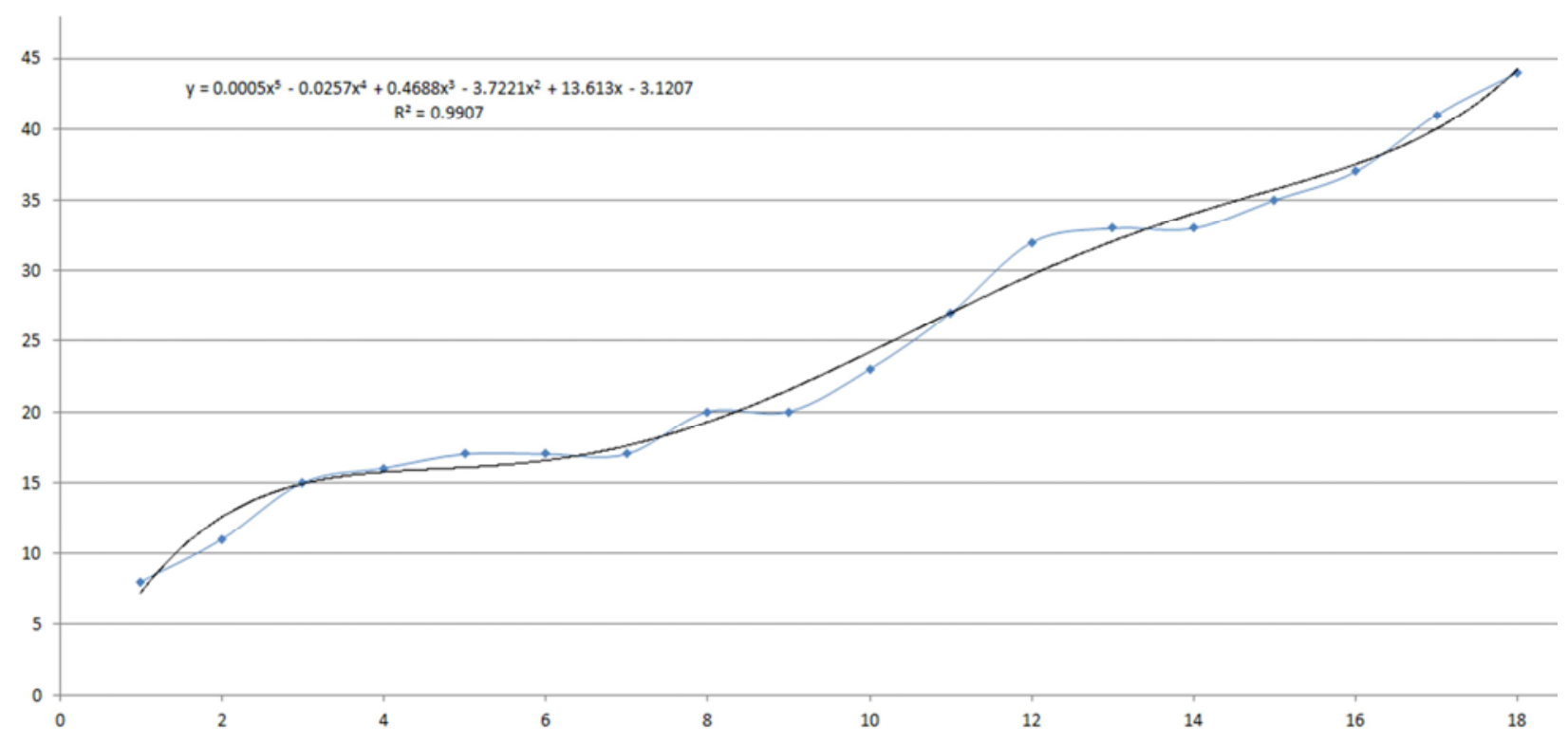

Figure 5. Polynomial fit of the infusion model for computer users.

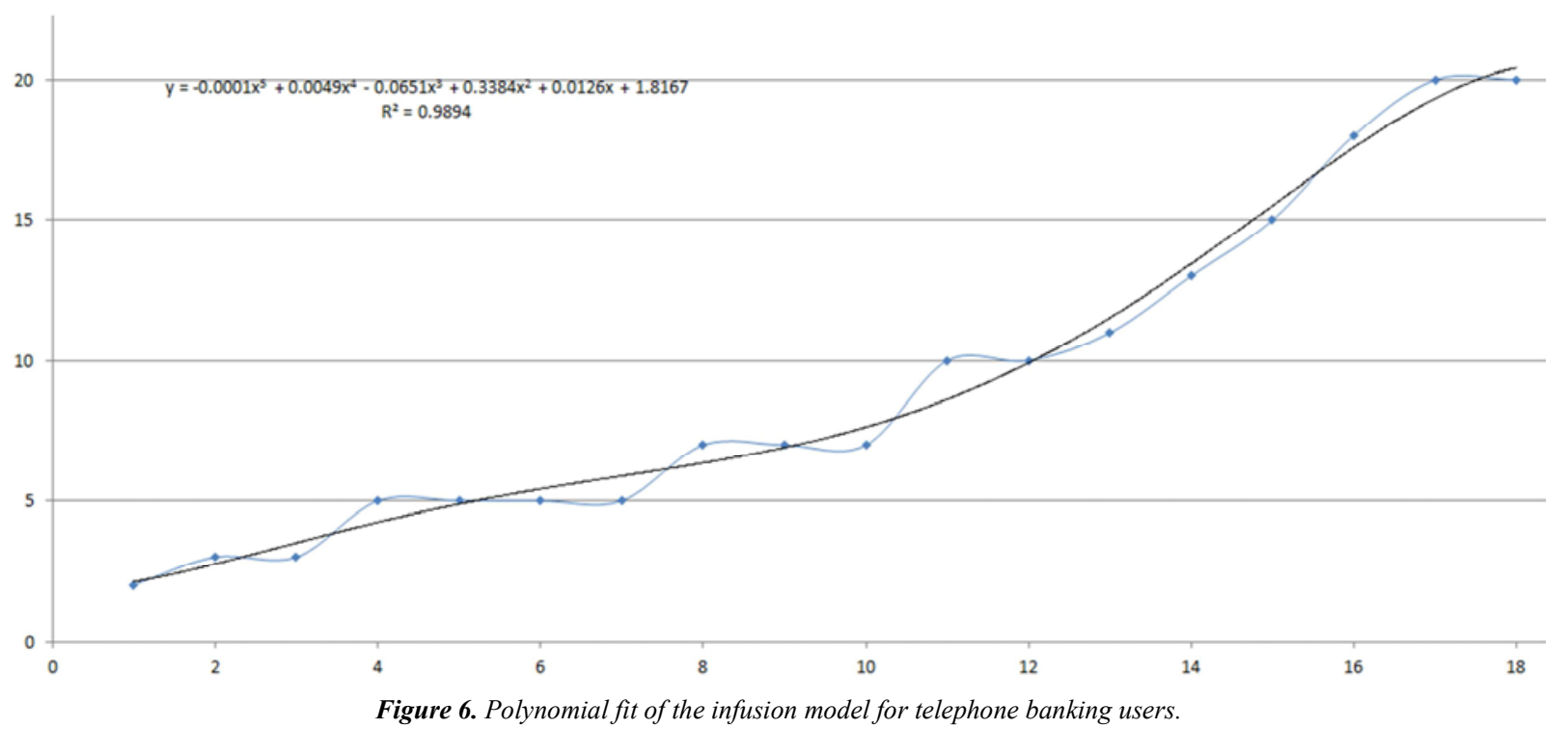

\section{e. Infusion model for the use of telephone banking}

Following the results of cumulative sum of the number of users of telephone banking users among microfinance banks in Nigeria, it was observed that the year of infusion was 1999 with 2 initial users. Using equation 1, the number of years from 1999 till 2016 is 18 years which corresponds to the 18 points of the cumulative frequency distribution curve shown in figure 6 . In figure 6 , the base year, $Y_{0}$ is point $x=1$ which corresponds to 2 on the y-axis while each consecutive year, $Y_{x}$ on the $x$-axis corresponds to the total number of users of telephone banking $\mathrm{x}$ years after the base year (year of infusion). Using the auto-generated polynomial that forms 
the best fit (black line) for the use of telephone banking from the cumulative distribution in table 8 , the results showed that the infusion model for the use of telephone banking can be

$$
S(x)=-0.0001 x^{5}+0.0049 x^{4}-0.065 x^{3}+0.338 x^{2}+0.0126 x+1.8167
$$

\section{f. Infusion model for the use of MICR technologies}

Following the results of cumulative sum of the number of users of MICR technologies users among microfinance banks in Nigeria, it was observed that the year of infusion was 1999 with 1 initial user. Using equation 1 , the number of years from 1999 till 2016 is 18 years which corresponds to the 18 points of the cumulative frequency distribution curve shown in figure 7 . In figure 7 , the base year, $Y_{0}$ is point $x=1$ which corresponds to 1 on the $y$-axis while each consecutive year, represented using a polynomial of degree $m=5$ as shown in equation 10 which had a coefficient of determination, $\mathrm{R}^{2}=0.9894$.

$\mathrm{Y}_{\mathrm{x}}$ on the $\mathrm{x}$-axis corresponds to the total number of users of MICR technologies $x$ years after the base year (year of infusion). Using the auto-generated polynomial that forms the best fit (black line) for the use of MICR technologies from the cumulative distribution in table 8 , the results showed that the infusion model for the use of MICR technologies can be represented using a polynomial of degree $m=4$ as shown in equation 11 which had a coefficient of determination, $\mathrm{R}^{2}=0.9802$.

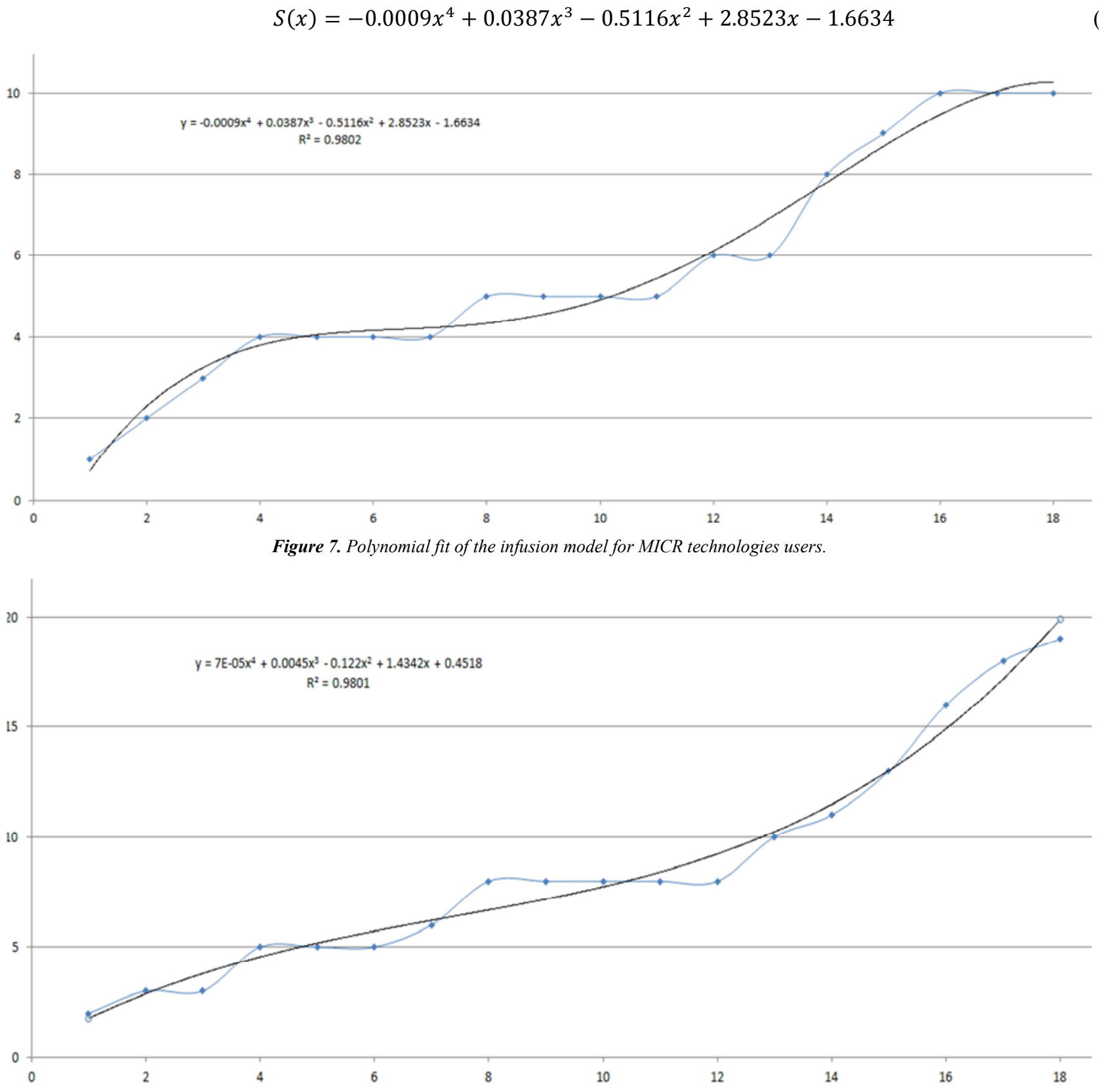

Figure 8. Polynomial fit of the infusion model for users of bank website/mobile app users. 
g. Infusion model for the use of bank website/mobile application

Following the results of cumulative sum of the number of users of bank website/mobile application users among microfinance banks in Nigeria, it was observed that the year of infusion was 1999 with 2 initial users. Using equation 1, the number of years from 1999 till 2016 is 18 years which corresponds to the 18 points of the cumulative frequency distribution curve shown in figure 8. In figure 8 , the base year, $Y_{0}$ is point $\mathrm{x}=1$ which corresponds to 2 on the $\mathrm{y}$-axis while each consecutive year, $\mathrm{Y}_{\mathrm{x}}$ on the $\mathrm{x}$-axis corresponds to the total number of users of bank website/mobile application $\mathrm{x}$ years after the base year (year of infusion). Using the autogenerated polynomial that forms the best fit (black line) for the use of bank website/mobile application from the cumulative distribution in table 8 , the results showed that the infusion model for the use of bank website/mobile application can be represented using a polynomial of degree $m=5$ as shown in equation 12 which had a coefficient of determination, $\mathrm{R}^{2}=0.9802$.

$$
S(x)=-0.0001 x^{5}+0.0049 x^{4}-0.065 x^{3}+0.338 x^{2}+0.0126 x+1.8167
$$

\section{h. Infusion model for the use of teleconferencing}

Following the results of cumulative sum of the number of users of teleconferencing users among microfinance banks in Nigeria, it was observed that the year of infusion was 1999 with 1 initial user. Using equation 1, the number of years from 1999 till 2016 is 18 years which corresponds to the 18 points of the cumulative frequency distribution curve shown in figure 9. In figure 9, the base year, $Y_{0}$ is point $\mathrm{x}=1$ which corresponds to 1 on the $y$-axis while each consecutive year,
$Y_{x}$ on the $x$-axis corresponds to the total number of users of teleconferencing $\mathrm{x}$ years after the base year (year of infusion). Using the auto-generated polynomial that forms the best fit (black line) for the use of teleconferencing from the cumulative distribution in table 8 , the results showed that the infusion model for the use of teleconferencing can be represented using a polynomial of degree $m=5$ as shown in equation 13 which had a coefficient of determination, $\mathrm{R}^{2}=0.9851$.

$$
S(x)=-0.0002 x^{5}+0.0087 x^{4}-0.135 x^{3}+0.824 x^{2}+1.324 x+1.8235
$$

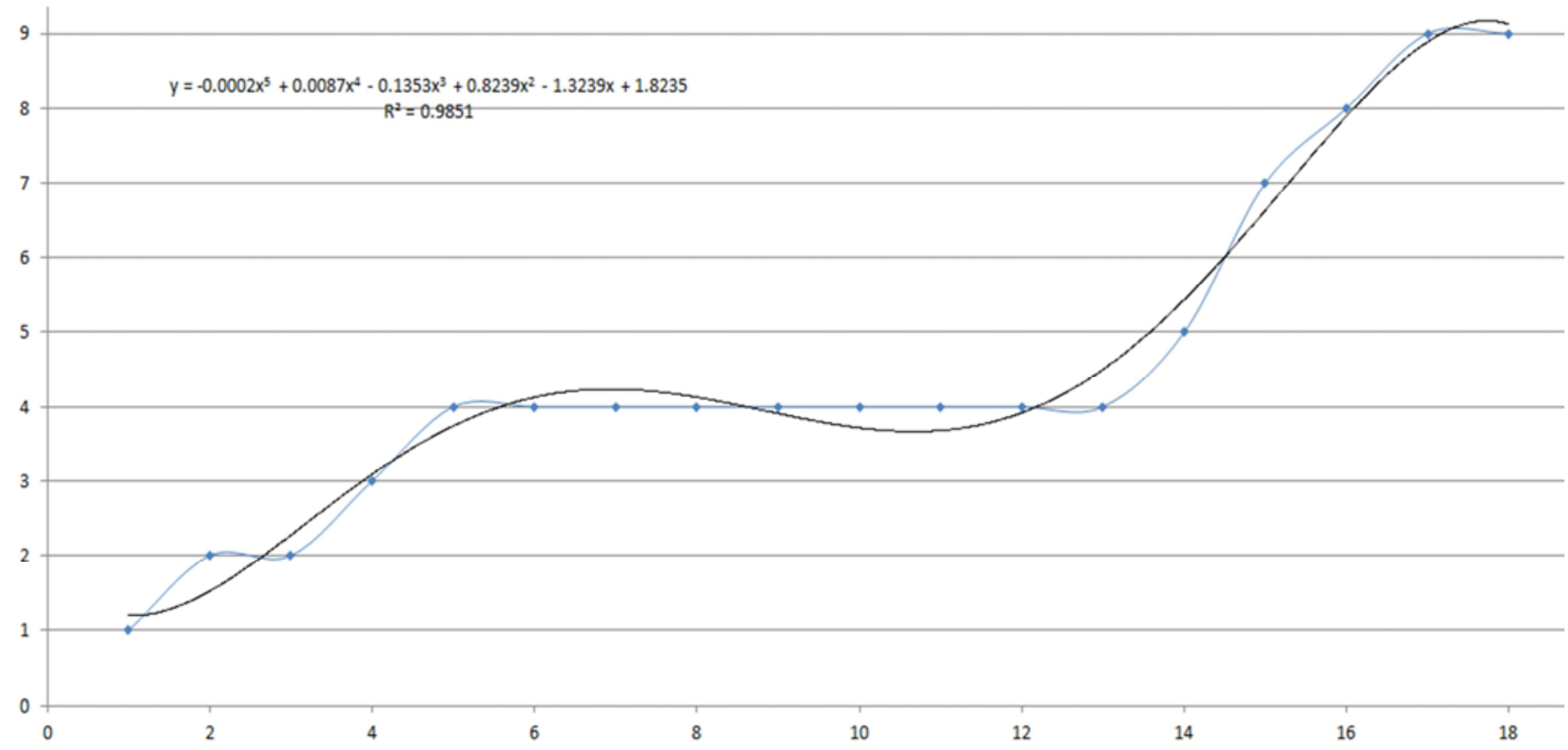

Figure 9. Polynomial fit of the infusion model for teleconferencing users. 


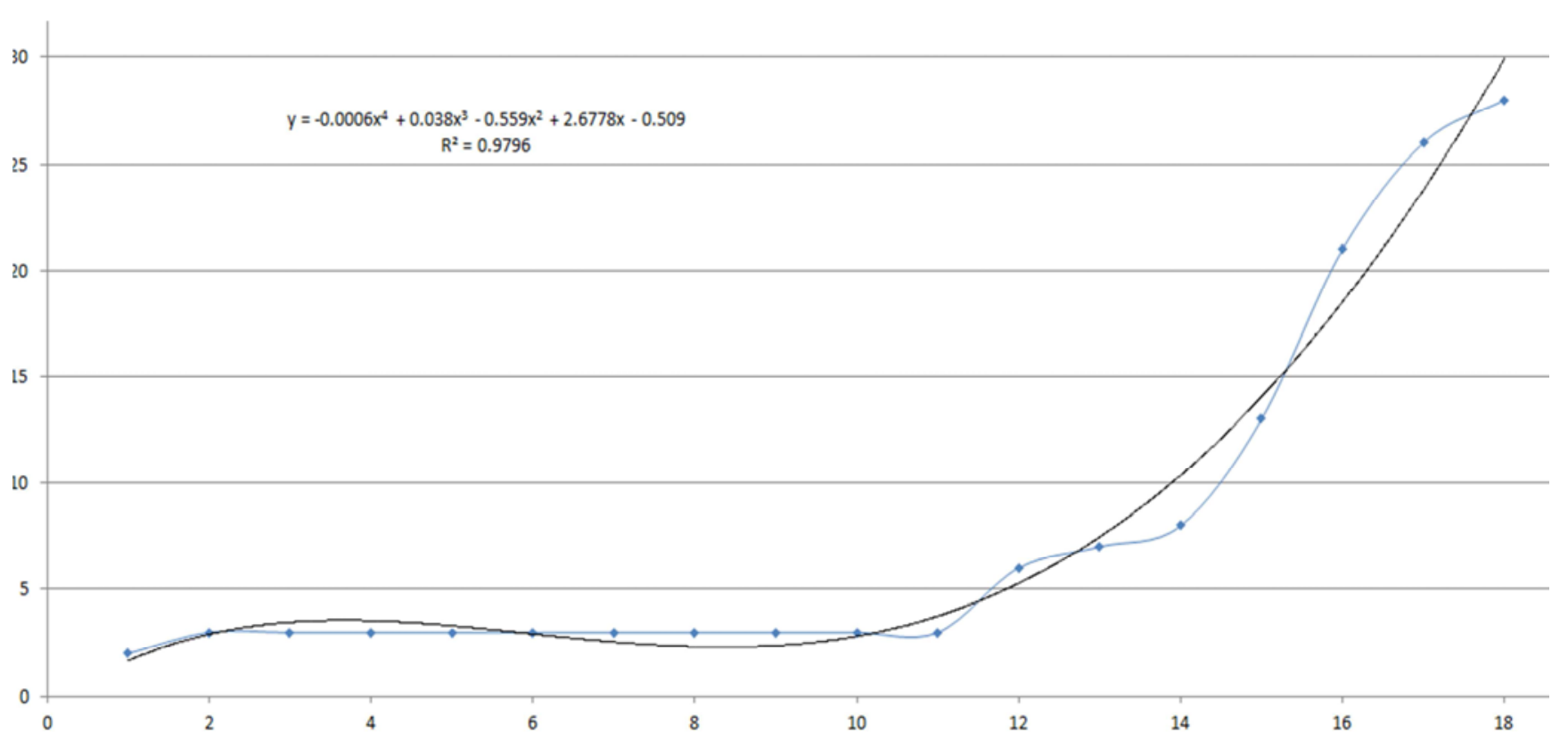

Figure 10. Polynomial fit of the infusion model for E-POS users.

\section{i. Infusion model for the use of E-POS}

Following the results of cumulative sum of the number of users of E-POS users among microfinance banks in Nigeria, it was observed that the year of infusion was 1999 with 2 initial users. Using equation 1, the number of years from 1999 till 2016 is 18 years which corresponds to the 18 points of the cumulative frequency distribution curve shown in figure 10 . In figure 10 , the base year, $Y_{0}$ is point $x=1$ which corresponds to 2 on the y-axis while each consecutive year,
$Y_{x}$ on the $x$-axis corresponds to the total number of users of E-POS $x$ years after the base year (year of infusion). Using the auto-generated polynomial that forms the best fit (black line) for the use of E-POS from the cumulative distribution in table 8 , the results showed that the infusion model for the use of E-POS can be represented using a polynomial of degree $m=4$ as shown in equation 14 which had a coefficient of determination, $\mathrm{R}^{2}=0.9796$.

$$
S(x)=-0.0006 x^{4}+0.038 x^{3}-0.559 x^{2}+2.6778 x+0.509
$$

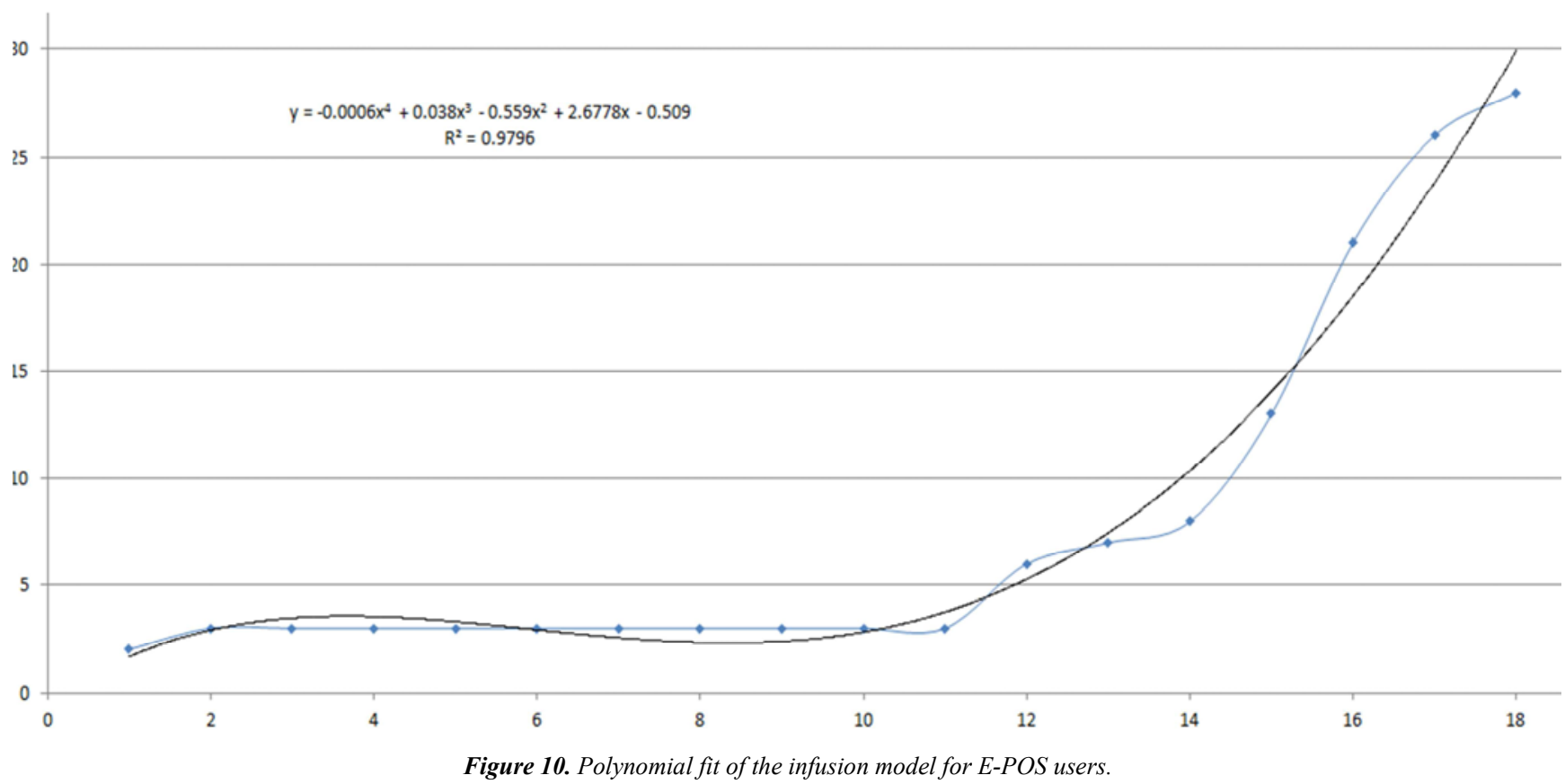




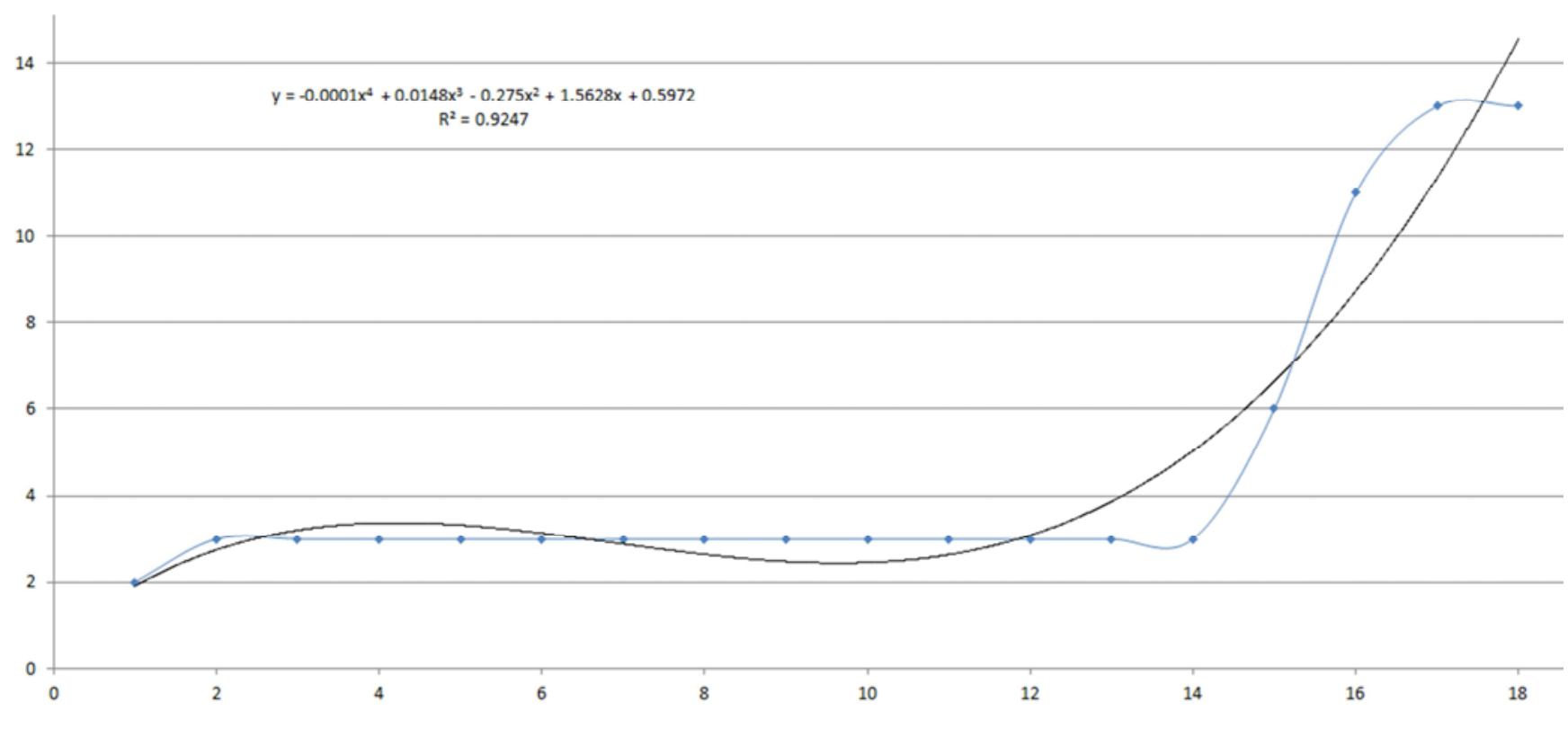

Figure 11. Polynomial fit of the infusion model for users of financial ERP software.

\section{j. Infusion model for the use of financial ERP software}

Following the results of cumulative sum of the number of users of financial ERP software users among microfinance banks in Nigeria, it was observed that the year of infusion was 1999 with 2 initial users. Using equation 1, the number of years from 1999 till 2016 is 18 years which corresponds to the 18 points of the cumulative frequency distribution curve shown in figure 10. In figure 10 , the base year, $Y_{0}$ is point $x=1$ which corresponds to 2 on the $\mathrm{y}$-axis while each consecutive year, $Y_{x}$ on the $\mathrm{x}$-axis corresponds to the total number of users of financial ERP software years after the base year (year of infusion). Using the auto-generated polynomial that forms the best fit (black line) for the use of financial ERP software from the cumulative distribution in table 8, the results showed that the infusion model for the use of financial ERP software can be represented using a polynomial of degree $m=4$ as shown in equation 15 which had a coefficient of determination, $\mathrm{R}^{2}=0.9247$.

$$
S(x)=-0.0001 x^{4}+0.0148 x^{3}-0.275 x^{2}+1.5628 x+0.5972
$$

\section{Conclusions}

This study revealed the infusion of ICT devices used among respondents selected from nine (9) microfinance institutions in Nigeria. Based on the findings of this study, the ICT devices identified to be used among the 126 respondents chosen for this study were: smartphones, SMS, e-mails, computer hardware, telephone banking, magnetic ink character recognition (MICR) cheque, bank websites or mobile banking applications, teleconferencing, electronic point-of-sale (E-POS) services and financial ERP software applications.

Following the analysis of the information collected using 126 questionnaires distributed among the respondents of the microfinance institutions selected for this study, a number of observations were made. Majority of respondents who used ICT were respondents who used ICT tools were customers who were traders with a majority age group of around 21-30 years. Majority of bank staff selected were loan officers with BSc/BA academic degrees. There was an equal distribution between married and single individuals. The results of this study also showed that the adoption of computers and smartphones influenced the adoption of SMS, e-mails, EPOS, bank website/mobile applications and telephone banking services at microfinance institutions and in the discharge of the duties of members of staffs.

The results of the study also showed that all ICT devices were adopted in the same year (1999) but the most commonly adopted ICT devices were: smartphones, SMS, computers and electronic point-of-sale (E-POS) services especially among bank customers. The results showed that the infusion model developed using a polynomial expression of a certain degree $m$ in terms of $x$ - the number of years after ICT infusion/adoption could be used to estimate the number of users adopting an ICT technology.

\section{References}

[1] Bada, J. K. (2012). ICT for business services: The case of Ugandan microfinance institutions. International Journal of Research and Reviews in Applied Sciences 11 (1): 140-152.

[2] Bamiro, O. A. (2011). Mastery of Technology for Junior School Certificates Examination. Ibadan: Evans Publishers: 343-347.

[3] Idowu, P. A., Adagunodo, E. R. and Adedoyin, R. (2006). Information technology infusion model for health sector in a developing country: Nigeria as a case. Technology and Healthcare, 14, 69-77. 
[4] Idowu, P. A., Eyitope, O and Idowu, B. (2003). Information and Communications Technology in Nigeria - The Health Sector Experience. Journal of Information Technology Impact, $3(2), 69-73$.

[5] Frankiewicz, C. (2003). Information Technology as a strategic tool for Microfinance in Africa. A seminar Report, April 2627, 2016 at Nairobi, Kenya.

[6] Srinivasan, R. and Sriram, M. S. (2003). Microfinance: An introduction. IIMB Management Review: 52 - 53.

[7] Mishra, B. L. and Chowbwy, M. (2009). Impact assessment of technology adoption in microfinance in India. Working Paper, Centre for Microfinance Research, Bankers Institute of Rural Development, Chandragupta Institute of Management, Patna.

[8] O'Flynn, M. (2008). ePayment: Powering West Africa. Card Technology Today: $10-11$.

[9] CGAP Microfinance Gateway (2013). Technology FAQs. Retrieved from http://www.microfinancegateway.org/p/site/m/template.rc/1.11 $.48240 / 1.26 .9192$

[10] Laudon, D. P. and Laudon, J. P. (2001). Management Information System: Organization and Technology in the Network Enterprises $4^{\text {th }}$ edition. Prentice Hall International, U. S. New American Corporation, New York: Dutton.

[11] Turban, E. and King, D. (2003). Introduction to E-Commerce. New Jersey: Pearson Education.

[12] Khattab, I., Balola, Y and Eldabi, T. (2012). Factors influencing branchless banking for microfinance in Sudan: Theoretical perspectives and future directions. In the Proceedings of the European, Mediterranean \& Middle Eastern Conference on Information Systems.

[13] European Microfinance Network (2012). The use of technology in microfinance. Retrieved from http://www.fgda.org/dati/ContentManager/files/The-use-oftechnology-in-Microfinance. pdf on June 23, 2016.
[14] Epstein, M. J. and Yuthas, K. (2010). Mission impossible: diffusion and drift in the microfinance industry. Sustainability Accounting, Management and Policy Journal 1 (2): 201 - 221.

[15] Microfinance Africa (2011). Pakistan: Branchless banking carries out Rs 59bn transactions till September. Retrieved from http://microfinanceafrica.net/tag/branchless-banking/ on June 25, 2016.

[16] Conflux Technologies (2010). Management Information System for Microfinance Institute. Retrieved from http://www.confluxtechnologies.com/1/post/2010/06/manage ment-information-system-for-microfinance-institute.html on June 23, 2016.

[17] Dailey, P. and Firpo, J. (2007). Microfinance and branchless banking: Models, constraints and recommendations. In Proceedings of the Widening Harmonized Access to Microfinance (WHAM) and Advancing Microfinance for Postdisaster Economic Reconstruction (AMPER) Projects.

[18] Akintaro, S. (2011). Going Cashless: Knock! Knock!! Here comes the e-era. Retrieved 19 June 2013 from http://www.ittelecomdigest.com/cover12-dec.htm on June 24 , 2016.

[19] Kruger, H., Drevin, L. and Steyn, T. (2006). A framework for evaluating ICT security awareness. In Proceedings of International Information Security South African Conference at North-West University - Potchefstroom Campus, Johannesburg (5-7 July, 2006). ISBN: 1-86854-636-5.

[20] Agbolade, O. K. (2011). Information and Communication Technology and Banks Profitability in Nigeria. Australian Journal of Business and Management Research 1 (4): 102 107.

[21] Dauda, Y. A. and Akingbade, W. A. (2011). Technology Innovation and Nigerian Banks Performance: The assessment of employees' and customer's responses. American Journal of Social and Management Sciences 2 (3): 329 - 340. 